\title{
Serologic Study of Febrile Upper Respiratory Tract Infections in Adults
}

\author{
Kaoru SHIMOKATA, Yasunobu TOTANi, Hiroshi TSUNEKAWA, \\ Harumi SASOU and Takuya MIYACHI
}

\begin{abstract}
We prospectively studied serum antiviral antibody response in adult patients with febrile upper respiratory tract infections. Paired sera were obtained in 158 patients from January 1982 to December 1983. Eighteen patients (11.4 percent) showed a significant antibody rise in the convalescent phase of the disease compared to the acute phase. Significant antibody rise was observed against all viruses examined: influenza viruses type $A$ and $B$, adenovirus type 3, respiratory syncytial virus, and parainfluenza viruses type 1, 2 and 3. Two patients responded simultaneously to two viruses. Serum interferon was detected in acute phase of the disease in 4 of 8 patients examined in whom viral infections were proved. Detected interferon was alpha type.
\end{abstract}

Key Words: $\quad$ Upper respiratory tract infection, Virus, Antibody, Interferon

Upper respiratory tract illness is probably the most common disease. Although it is considered that most pathogens of upper respiratory tract infections are viruses, precise analysis of the pathogens has been unsatisfactory, especially in adults. This might be due to the difficulty in isolating viruses and obtaining acute and convalescent sera because of the earlier recovery of the disease. We report here the prospective study on the causative viruses in adult patiens with febrile upper respiratory tract infections using serologic analysis, interferon titers in sera of these patients, and laboratory findings.

\section{PATIENTS AND METHODS}

Subjects were adult patients with upper respiratory tract infections whose body temperature rose more than $37^{\circ} \mathrm{C}$. The diagnosis of upper respiratory tract infections was done by chest physicians. Patients who were suspected to be suffering from bacterial infections were excluded. They had no underlying diseases. For detecting changes in antibody titer, an acute phase serum was drawn within three days after the onset of illness, and convalescent phase serum two to three weeks later. Paired sera were obtained in 158 patients from January 1982 to December 1983. There were 90 male and 68 female patients.

Paired sera were analyzed for their antibody titers against influenza viruses type $\mathrm{A}$ and $\mathrm{B}$, adenovirus type 3 , and respiratory syncytial (RS) virus using a complement fixation test. Influenza viruses type $\mathrm{A}$ and $\mathrm{B}$ were grown in embryonated eggs and adenovirus type 3 was grown in HeLa cells in our laboratory and used for antigens. RS virus antigen was purchased from Denka Seiken Co., Ltd. (Tokyo). Complement was purchased from Kyokuto Pharmaceutical Industry Co., Ltd. (Tokyo). Inactivated $25 \mu 1$ serum (diluted 1:4), $25 \mu 1$ of properly diluted antigen and $25 \mu 1$ of complement $\left(5 \mathrm{CH}_{50}\right)$ were mixed together and incubated at $4^{\circ} \mathrm{C}$ overnight. Sheep erythrocytes sensitized with hemolysin (Nippon Biotest Laboratories, Tokyo) were added $(50 \mu 1)$ and

From The First Department of Internal Medicine, Nagoya University School of Medicine, Nagoya

Received for publication March 27, 1988

Reprint requests to: Kaoru Shimokata, MD, The First Department of Medicine,

Nagoya University School of Medicine, Tsurumai-cho, Showa-ku, Nagoya 466, Japan 
incubated at $37^{\circ} \mathrm{C}$ for $1 \mathrm{hr}$. The plates were centrifuged at 1,000 rpm for $3 \mathrm{~min}$ and observed for hemolysis. Complement fixation test was considered to be positive with hemolytic grade 4 (hemolysis 0 percent) or 3 (hemolysis 25 percent). The reciprocal of the highest dilution of the serum which showed hemolytic grade 4 or 3 was considered to be antibody titer.

Hemagglutination inhibition test was used for the serum antibody titrations against parainfluenza viruses type 1,2 and 3. For the elimination of non-specific hemagglutinating inhibitors, one volume $(200 \mu 1)$ of sera was treated with 3 volumes $(600 \mu 1)$ of receptor-destroying enzyme (RDE) (Takeda Chemical Industries Ltd., Tokyo) at $37^{\circ} \mathrm{C}$ overnight, and then RDE was inactivated at $56^{\circ} \mathrm{C}$ for $30 \mathrm{~min}$. Treated sera were diluted with the same volume of phosphate buffered saline (PBS). Non-specific hemagglutinin was absorbed by adding $50 \mu 1$ of 50 percent guinea pig erythrocytes, incubating at room temperature for $1 \mathrm{hr}$, and centrifuging at $2,000 \mathrm{rpm}$ for $20 \mathrm{~min}$. Then, sera were incubated with 4 units of each antigen at room temperature for $1 \mathrm{hr}$, added with guinea pig erythrocytes and further incubated at room temperature for $1 \mathrm{hr}$. The reciprocal of the highest dilution of the sample causing hemagglutination inhibition was considered as antibody titer. When the serum antibody titer in convalescent phase was at least four-fold higher than that in acute phase, we considered that viral infection was present.

Interferon assay was carried out according to the dye-uptake method in Fogh and Lund (FL) cells using vesicular stomatitis virus (VSV) as a challenge virus. A modification of the semimicromethod was used ${ }^{1)}$. In brief, an individual well of microtest plate flat for tissue culture (Falcon 3072, Oxnard, California, U.S.A.) was first filled with $50 \mu 1$ of Eagle minimum essential medium (MEM) buffered with sodium bicarbonate. To prepare a series of two-fold dilutions, $50 \mu 1$ of each 1:2 diluted serum sample was added to the first well containing an equal volume of medium, and serial dilutions were made by transferring $50 \mu 1$ of the mixture. Each well was then seeded with $50,000 \mathrm{FL}$ cells in $50 \mu 1$ of the medium supplemented with 3 percent fetal calf serum. After overnight incubation at $37^{\circ} \mathrm{C}$ in a $\mathrm{CO}_{2}$ incubator, medium in each well was discarded and infected with $100 \mathrm{TCID}_{50}$ of VSV in $100 \mu 1$ of the medium. Several wells in each plate served as virus controls, cell controls and standard interferon. Cells were observed for dye-uptake when the virus controls showed complete destruction by the virus. For the optical density (OD) reading, each well was filled with $100 \mu 1$ of 0.02 percent neutral red solution for $2 \mathrm{hr}$, and then washed with PBS two times. OD was read at 550 $\mu \mathrm{m}$ after pouring each well with $100 \mu 1$ of 50 percent ethanol containing $0.01 \mathrm{~N} \mathrm{HCl}$. The highest dilution of the sample causing 50 percent protection of cells was considered the end-point. Each sample was titrated in duplicate. Anti-human interferon- $\alpha$ monoclonal antibody (supplied from Takeda Pharmaceutical Co., Ltd., Osaka), and anti-human interferon- $\beta$ polyclonal antibody (supplied from Dr. Morishima, Nagoya University) were used for the confirmation of antiviral substance. Complete blood counts with differentials were examined in some patients. Paired $t$ test was used for statistical analysis.

\section{RESULTS}

\section{Seasonal distribution of patients}

We could observe febrile patients with upper respiratory tract infections in any month. However, many patients were observed in winter (Figure 1). There were 93 patients in winter, 17 in spring, 28 in summer and 20 in fall visiting the clinic.

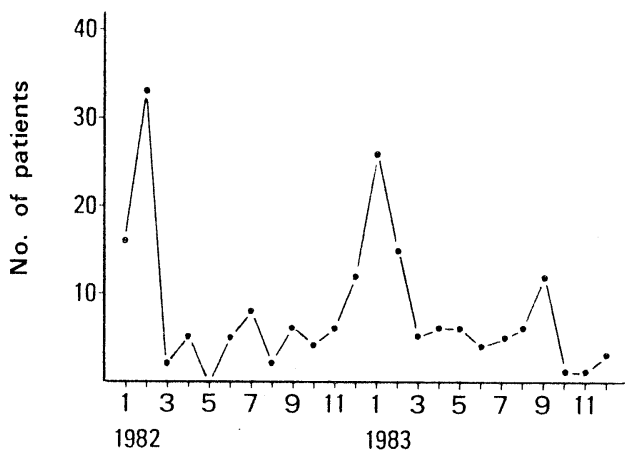

Fig. 1. Temporal distribution of adult patients with febrile upper respiratory tract infections. 
Table 1. Serum antibodies identified in 158 adult patients with febrile upper respiratory infections

\begin{tabular}{lcccc}
\hline Infecting virus & $\begin{array}{c}\text { Winter } \\
(\mathrm{n}=93)\end{array}$ & $\begin{array}{c}\text { Spring } \\
(\mathrm{n}=17)\end{array}$ & $\begin{array}{c}\text { Summer } \\
(\mathrm{n}=28)\end{array}$ & $\begin{array}{c}\text { Fall } \\
(\mathrm{n}=20)\end{array}$ \\
\hline Influenza A & 5 & 1 & & \\
Influenza B & 5 & & & \\
Adeno 3 & 1 & 1 & 1 & \\
RS & 2 & & & \\
Parainfluenza 1 & 2 & & & \\
Parainfluenza 2 & 1 & & & \\
Parainfluenza 3 & & 1 & & \\
\hline total & $16(17.2)^{2)}$ & $3(17.6)$ & $1(3.6)$ & 0 \\
\hline
\end{tabular}

1) Winter (December-February), Spring (March-May), Summer (June-August), and Fall (SeptemberNovember)

2) Number in parentheses indicates percentage.

Number of serum with significant elevation of antibody titer

Eighteen out of 158 patients (11.4 percent) showed a significant rise of antibody titer. Simultaneous rises of antibody titers against two different viruses were observed in two patients, that is, influenza viruses type $A$ and $B$ in one patient, and adenovirus type 3 and parainfluenza virus type 3 in another. Therefore, we could observe the rises of antibody titer 20 times in 18 patients. There were 6 significant rises of antibody titers in influenza virus type A, 5 in influenza virus type B, 3 in adenovirus type 3, 2 in RS virus and parainfluenza virus type 1 , and one in parainfluenza virus type 2 and 3 (Table 1).

\section{Seasonal rise of antibody titer}

Significant rises of antibodies were observed 16 times in 93 patients (17.2 percent) in winter, 3 times in 17 patients (17.6 percent) in spring, and one time in 28 patients (3.6 percent) in summer (Table 1). Serologic examination proved that influenza viruses type $\mathrm{A}$ and $\mathrm{B}, \mathrm{RS}$ virus and parainfluenza virus infections were observed especially in winter and that adenovirus type 3 infections were observed in winter, spring and summer (Table 1).
Measurement and characteristics of serum interferons

We measured serum interferon titers in 8 patients whose sera showed significant rises of anti-viral antibody titers. Five patients were infected with influenza virus type A, 2 with influenza virus type $B$ and 1 with parainfluenza virus type 2. As shown in Table 2, we detected serum interferons in 4 of 8 patients in the acute phase of the disease, but not in the convalescent phase. Neutralization test using anti-interferon $\alpha$ antibody or anti-interferon $\beta$ antibody in representative 4 patients revealed that the treatment with the former antibody completely abolished the interferon activity, whereas the treatment with the latter antibody did not affect the interferon activity (Table 3 ).

\section{Complete blood count and differentials}

White blood cells (WBC) were $8300 \pm 3100 / \mathrm{mm}^{3}$ (mean \pm 1SD) in acute stage and $6200 \pm 1700 / \mathrm{mm}^{3}$ in convalescent stage $(n=100)$. There was a significant difference between them $(p<0.001)$.

Table 2. Serum interferon titers in acute and convalescent phases.

\begin{tabular}{lcc}
\hline \multirow{2}{*}{ Infecting virus } & \multicolumn{2}{c}{ Interferon titer $^{1)}$} \\
\cline { 2 - 3 } & $\begin{array}{c}\text { Acute } \\
\text { phase }\end{array}$ & $\begin{array}{c}\text { Convalescent } \\
\text { phase }\end{array}$ \\
\hline Influenza A & 56 & $<20$ \\
Influenza A & 40 & $<20$ \\
Influenza A & 56 & $<20$ \\
Influenza A & $<20$ & $<20$ \\
Influenza A & $<20$ & $<20$ \\
Influenza B & $<20$ & $<20$ \\
Influenza B & $<20$ & $<20$ \\
Parainfluenza 2 & 40 & $<20$ \\
\hline
\end{tabular}

1) $\mathrm{IU} / \mathrm{ml}$

Table 3. Characterization of serum interferons.

\begin{tabular}{lccc}
\hline \multirow{2}{*}{ Infecting virus } & \multicolumn{3}{c}{ Treatment } \\
\cline { 2 - 4 } & control & anti IFN- $\alpha$ & anti IFN- $\beta$ \\
\hline Influenza A & $56^{1)}$ & $<20$ & 56 \\
Influenza A & 40 & $<20$ & 40 \\
Influenza A & 56 & $<20$ & 56 \\
Parainfluenza 2 & 40 & $<20$ & 40 \\
\hline
\end{tabular}

1) $\mathrm{IU} / \mathrm{ml}$ 
Table 4. Hematological findings in adult patients with febrile upper respiratory infections.

\begin{tabular}{lccc}
\hline & Acute phase & \multicolumn{1}{c}{ Convalescent } & phase \\
\hline WBC $(n=100)$ & $8300 \pm 3100^{1)}$ & $6200 \pm 1700$ & $\mathrm{p}<0.001$ \\
Band neutrophil $(\mathrm{n}=96)$ & $9 \pm 8^{2)}$ & $4 \pm 2$ & $\mathrm{p}<0.001$ \\
Polymorphonuclear & & & \\
neutrophil $(\mathrm{n}=96)$ & $69 \pm 12$ & $55 \pm 11$ & $\mathrm{p}<0.001$ \\
Lymphocyte $(\mathrm{n}=96)$ & $16 \pm 8$ & $33 \pm 9$ & $\mathrm{p}<0.001$ \\
\hline
\end{tabular}

1) mean $\pm \mathrm{SD}\left(/ \mathrm{mm}^{3}\right)$

2) mean $\pm S D$ (percent)

In differentials, band neutrophil was $9 \pm 8$ percent in acute stage and $4 \pm 2$ percent in convalescent stage, polymorphonuclear neutrophil was $69 \pm 12$ percent in acute stage and $55 \pm 11$ percent in convalescent stage, and lymphocyte was $16 \pm 8$ percent in acute stage and $33 \pm 9$ percent in convalescent stage $(n=96)$. There were significant differences between acute and convalescent phases $(\mathrm{p}<0.001$, respectively) (Table 4).

\section{DISCUSSION}

Adults experience an average of one to three and children three to six respiratory illnesses each year ${ }^{2)}$. Infections with respiratory syncytial virus, parainfluenza viruses and adenoviruses are common in children. The most commonly identified agents of upper respiratory tract infections among adults are rhinoviruses followed by coronaviruses $^{3)}$. Rhinoviruses have been associated with approximately a third of colds in adults. The other respiratory viruses (i,e, parainfluenza viruses, respiratory syncytial virus, influenza viruses, adenoviruses, and coronaviruses) have been implicated in another third of colds. The remaining third of colds are still of undetermined etiology, and are presumably due to either known viruses which are missed due to the insensitivity of currently available diagnostic methods or to new agents which have not been identified ${ }^{4}$.

Diagnostic tests available to the clinician include serologic and antigen detection tests and viral isolation. Serologic test has the advantage that serum specimens are generally easier to handle, but this test requires both acute and convalescent sera for comparison of antibody titers. Consequently, results are usually not available when clinically useful. Generally, viral isolation is more sensitive than antigen detection but takes longer and is more expensive.

We studied serologic test, but we did not involve the antibody titration of rhinoviruses and coronaviruses in our series. The reason is as follows. Firstly, identifying rhinovirus and coronavirus infections is difficult. Because of the numerous serologic types, testing for antibody rises in sera is not presently practical. Secondly, we chose febrile patients whose temperature exceeded $37^{\circ} \mathrm{C}$. Systemic symptoms such as malaise, feverishness, chills, and myalgia are not prominent in adults with rhinovirus and coronavirus infection ${ }^{5,6)}$. Therefore, there might be few patients infected with rhinoviruses or coronaviruses in our series.

In the present study, there were clear antibody titer rises in 18 (11 percent) of 158 patients. Reed stated that influenza viruses, parainfluenza viruses, respiratory syncytial virus and adenoviruses cause $15-20$ percent of common colds ${ }^{7)}$. Parainfluenza viruses, respiratory syncytial virus, influenza viruses, adenoviruses and coronaviruses have been associated with about a third of the colds in adults ${ }^{4}$. Ten percent of common colds may be due to coronaviruses ${ }^{8)}$. In a series of 543 febrile upper respiratory tract infections, respiratory syncytial, influenza, parainfluenza and adenoviruses were recovered from 127 specimens (23.4 percent $)^{9}$. From these figures, we postulated that viruses studied in the present study would be associated with about 20 percent of colds. However, the percentage obtained was lower than expected. Although the reason is not clear, it would be possible that the patients we studied were limited to febrile ones and the method we used was less sensitive than virus isolation.

We also studied the interferon titer in 8 of 18 patients who were proved to have viral infections. Sera from 4 of these 8 patients showed detectable interferon titer in the acute phase of infection. Detected interferon was alpha type. Possible explanations why only interferon $\alpha$ was detected in the serum in our series could be presented as follows. Perhaps both interferon $\alpha$ and interferon $\beta$ are produced at the infected site. However, interferon $\beta$ is less stable than interferon $\alpha$ in the blood $^{10)}$, so it would be eliminated. An alternative 
explanation is that interferon $\beta$ is adsorbed and thus retained at the site of production easier than interferon $\alpha$. Viral infectious diseases in upper respiratory tract are usually mild. Therefore, interferons produced at the morbid site might not be numerous, and it would not be surprising that such interferons were not detected in sera of all patients studied. Although we could not find interferon in sera of all patiens studied, these interferons may play an important role for the recovery from viral infections ${ }^{11-13)}$. As for leukocyte response during viral respiratory illness in man, Douglas et al. ${ }^{14)}$ reported that there were increase in neutrophils and decrease in lymphocytes early in illness in volunteers inoculated with respiratory viruses. We also obtained the same results, although our observations based on the infections naturally occurred. For antigen detection, monoclonal antibodies are likely to be commonly used. Tests for detecting viral DNA or other virus specific components in clinical specimens are also being developed and may further improve our ability to detect viral respiratory infections.

\section{REFERENCES}

1) Shimokata K: Studies on the pathogenicity of human-origin parainfluenza virus in the brain of mice. Microbiol Immunol 22: 533, 1978.

2) Monto AS, Ullman BM: Acute respiratory illness in an American community: The Tecumseh study. JAMA 227: 164, 1974.

3) Anderson LJ, Patriarca PA, Hierholzer JC, et al: Viral respiratory illnesses. Med Clin North Am 67: 1009, 1983.
4) Gwaltney JM Jr: Rhinoviruses and coronaviruses virological aspects of their role in causing colds in man. Eur J Respir Dis 64 (Suppl 128): 336, 1983.

5) Gwaltney JM Jr, Hendley JO, Simon G, et al: Rhinovirus infections in an industrial population. II. Characteristics of illness and antibody response. JAMA 202: 494, 1967.

6) Hendley JO, Fishburne HB, Gwaltney JM Jr; Coronavirus infections in working adults. Eight-year study with 229E and OC43. Am Rev Respir Dis 105: 805, 1972.

7) Reed SE: The aetiology and epidemiology of common colds, and the possibilities of prevention. Clin Otolaryn 6: 379, 1981.

8) Tyrrell DAJ: Rhinoviruses and coronaviruses virological aspects of their role in causing colds in man. Eur J Respir Dis 64 (Suppl 128): 332, 1983.

9) Kawana R: Clinicovirological studies of the cold syndrome, with primary reference to rhinoviruses and coronaviruses. Asian Med J 21: 631, 1978.

10) Edy VG, Billiau A, De Sommer P: Non-appearance of injected fibroblast interferon in circulation. Lancet i: 451, 1978.

11) Gresser I, Tovey MG, Bandu MT, et al: Role of interferon in the pathogenesis of virus disease in mice as demonstrated by the use of anti-interferon serum. I. Rapid evolution of EMC virus infection. J Exp Med 144: 1305, 1976.

12) Gresser I, Tovey MG, Maury C, et al: Role of interferon in the pathogenesis of virus disease in mice as demonstrated by the use of anti-interferon serum. II. Studies with herpes simplex, Morony sarcoma, vesicular stomatitis, Newcastle disease and influenza viruses. J Exp Med 144: 1316, 1976.

13) Isaacs D, Clark JR, Tyrrell DAJ, et al: Deficient production of leukocyte interferon (interferon- $\alpha$ ) in vitro and in vivo in children with recurrent respiratory tract infection. Lancet ii: $950,1981$.

14) Douglas RG Jr, Alford RH, Cate TR, et al: The leucocyte response during viral respiratory illness in man. Ann Intern Med 64: 521, 1966. 